Agredo, Vella, $M u-C R M$ Evaluation: International Symposium of the Analytic Hierarchy

Process 2016, London, U.K.

\title{
EVALUATION OF CUSTOMER RELATIONSHIP MANAGEMENT (CRM) SYSTEMS USING AN AHP APPROACH
}

\begin{tabular}{|c|l|}
\hline $\begin{array}{c}\text { Shannon Agredo } \\
\text { Catherine Vella } \\
\text { Enrique Mu (Faculty Sponsor) }\end{array}$ & $\begin{array}{l}\text { sagredo@live.carlow.edu } \\
\text { cavella@live.carlow.edu }\end{array}$ \\
\hline emu@,carlow.edu \\
\hline
\end{tabular}

\begin{abstract}
This study will use an analytic hierarchy approach toward the evaluation of a suitable CRM system. Although the evaluation will be done within the context of a specific business, the analysis will be done in a way that this model and our cost-benefit analysis can be useful as a learning and reference tool for other CRM decision-makers.
\end{abstract}

Keywords: customer relationship management, CRM, AHP cost-benefit.

\section{Introduction}

The motivation for this study is based on the need to decide whether a specific organization should replace its existing CRM system. On of the co-authors is personally involved with the decision and suggested the application of an AHP approach for this.

\section{Literature Review}

We will first review key literature on CRMs and based on this we will perform a preliminary identification of the benefits and costs to be considered. In addition, expert opinion from the client organization will be also gathered.

\section{Hypotheses/Objectives}

This study intends to identify the key factors to take into consideration when performing a CRM evaluation as well as to show how to use AHP cost benefit analysis for this purpose.

\section{Research Design/Methodology}

1 All participants are affiliated with Carlow University, Pittsburgh, PA. USA. 
Agredo, Vella, $M u-C R M$ Evaluation: International Symposium of the Analytic Hierarchy

Process 2016, London, U.K.

The methodology will consist in first, to identify decision factors for CRM evaluation based on information from extant literature, next to gather requirements from the client organization and based on these two sources we will identify the costs and benefits and will develop the respective decision models (a different hierarchy for each type of factor). Criteria weighting will be done by a key representative(s) from the client in a face-to-face environment and the cost-benefit evaluation will be done by the authors.

\section{Data/Model Analysis}

In principle, a specific hierarchy for benefits and costs will be developed. However, inclusion of opportunities and risks is also possible.

\section{Limitations}

Given that this project is still currently under development, we cannot identify any limitations yet; however, case-based decisions are usually questioned in terms of generalizability.

\section{Conclusions}

What we expect to conclude from this study is first, learning the key factors in adopting a CRM system; second, understanding and also providing a cost-benefit analysis that can serve as a reference and best practice for AHP practitioners.

\section{Key References}

$\mathrm{Mu}$, E. (2016). Using AHP BOCR analysis for experiential business education and prioritization of international opportunities. International Journal of Business and Systems Research, 10(2/3/4), 364-392.

$\mathrm{Mu}$, E. and Pereyra-Rojas, M. (forthcoming 2016). Practical decision making: An introduction to the Analytic Hierarchy Process using Super Decisions. Springer: N.Y.

Saaty, T.L., \& Peniwati, K. (2007). Group decision-making: Drawing out and reconciling differences. Pittsburgh, PA: RWS Publications.

\section{Appendices}

n/a. 